\title{
CHANGES IN THE COMPOSITION OF SHEEP FETAL FLUIDS DURING EARLY PREGNANCY
}

\author{
R. G. WALES AND R. N. MURDOCH \\ Department of Veterinary Physiology, University of Sydney, \\ Sydney 2006, N.S.W., Australia
}

(Received 7th March 1972)

Summary. The composition of sheep fetal fluids obtained on Days 22, 31 and 44 of pregnancy has been studied.

The osmotic pressure of allantoic fluid was low and its volume increased twofold between Days 31 and 44 of pregnancy. A seventeenfold increase in volume occurred in the amniotic fluid over the same period.

Fructose was the main reducing sugar present and increased in concentration in the allantoic fluid between Days 31 and 44 of pregnancy. During this time, the allantoic fluid also showed an increase in sorbitol, protein, amino acids, calcium and magnesium and a decrease in lactic acid, potassium and bicarbonate. Amniotic fluid was more constant in composition and had a lower total reducing sugar, fructose, protein, sorbitol, amino acid, calcium and magnesium content and higher sodium, potassium and chloride content than allantoic fluid. Phosphorus occurred in low concentration in both fluids.

Glutamic acid was the only acidic amino acid present in allantoic fluid and occurred in lower concentration than glutamine. Alanine and glycine were the major neutral amino acids, with lower concentrations of serine, valine, threonine and leucine/isoleucine being present. Basic amino acids made up about $30 \%$ of the total. Substantial increases occurred in the concentrations of alanine, glutamic acid, glutamine and serine in the allantoic fluid between Days 31 and 44 of pregnancy.

The changes in the composition of allantoic fluid suggest that major developmental changes in metabolic activity are occurring in the sheep fetus between Days 31 and 44 of pregnancy.

\section{INTRODUCTION}

As the composition of the fetal fluids of sheep and other placental mammals is influenced by the excretion of fetal urine, changes in the concentration of a number of their components during early pregnancy may indicate the time at which major developmental changes in metabolic activity are occurring in the fetus. Most of our knowledge about sheep fetal fluids, however, is derived from studies of amniotic and allantoic fluids at postimplantation stages of pregnancy. In view of this, the composition of the fluids was examined at 
stages of pregnancy when implantation was being established and the amniotic and allantoic fluids were in an early stage of formation.

\section{MATERIALS AND METHODS}

\section{Materials}

Samples of allantoic and amniotic fluids were obtained from adult Merino ewes used in the experiments of Murdoch (1970). Ewes were mated with fertile rams (Day 0) and slaughtered by cutting the throat and dislocating the cervical vertebrae on Day 22, 31 or 44 of pregnancy. The uteri were removed, placed in crushed ice and quickly taken to the laboratory where the uterine horns were dissected to expose the fetal membranes. The volume and $\mathrm{pH}$ of the fluids were recorded immediately following their aspiration from the fetal membranes, $\mathrm{pH}$ being measured with a glass electrode. The fluids were then stored in polythene bottles at $-20^{\circ} \mathrm{C}$ until assay, which was carried out on the fluids from four ewes at each of the above stages of pregnancy. The amount of amniotic fluid accumulated on Day 22 of pregnancy was insufficient for analysis.

\section{Analytical methods}

A portion of the fluids was deproteinized with $0.5 \mathrm{vol} 5 \%(\mathrm{w} / \mathrm{v}) \mathrm{ZnSO}_{4} .7 \mathrm{H}_{2} \mathrm{O}$ and 0.5 vol $0.3 \mathrm{~N}-\mathrm{Ba}(\mathrm{OH})_{2}$ and total reducing sugars (Somogyi, 1952), fructose (Mann, 1948; White, 1959), glucose (Huggett \& Nixon, 1956), lactic acid (Barker \& Britton, 1957) and sorbitol (O'Shea \& Wales, 1965) were estimated in the neutral filtrate. Urea and ammonia were determined by the methods of Grünbaum \& Pace (1965) and protein by the method of Lowry, Rosebrough, Farr \& Randall (1951). The amino acid content of the fluids was determined according to the method described by Rosen (1957). Individual amino acids in allantoic fluid were separated by high-voltage electrophoresis and paper chromatography. Initially, aliquots of the fluid were subjected to high-voltage paper electrophoresis on Whatman No. 1 filter paper using formic acid-acetic acid buffer at $\mathrm{pH} 1.85$ and a voltage gradient of $100 \mathrm{~V} / \mathrm{cm}$ (Atfield \& Morris, 1961). Following electrophoresis, the electrophoretograms were developed by immersion in ninhydrin reagent $(0.25 \%$ ninhydrin in acetone) and heating the dried paper at $60^{\circ} \mathrm{C}$ for $20 \mathrm{~min}$. The ninhydrin-reactive zones were cut out together with appropriate blanks and the colour eluted with $75 \%$ (v/v) ethanol containing $12.5 \mathrm{mg} \mathrm{CuSO} / 100 \mathrm{ml}$. The resultant solutions were read in the spectrophotometer and the amount of each amino acid was expressed as a proportion of the total ninhydrin-reactive material eluted from the paper. With this system, neither glutamine and glutamic acid nor valine and serine could be separated. In order to obtain the relative proportions of these amino acids and to check the identity of the other amino acids, additional aliquots were separated by high-voltage electrophoresis as described above and the areas corresponding to the individual amino acid zones were eluted with water, dried and run on paper chromatography in a descending system using Whatman No. 1 paper. The solvent systems employed were $n$-butanol:acetic acid: water $(4: 1: 5)$, phenol: water $(4: 1)$ and ethanol: $7 \cdot 5 \mathrm{~N}$-ammonia:water 
$(8: 1: 1)$. The amino acids separated by electrophoresis behaved in these solvents as predicted and the ratios of glutamine to glutamic acid and serine to valine were determined spectrophotometrically as described above. In addition, the proportions of glutamic acid, neutral amino acids and basic amino acids were checked by high-voltage electrophoresis using phthalate buffer of pH 5.9 (Block, Durrum \& Zweig, 1958). Using the above data, the concentrations of individual amino acids in each fluid were determined from their proportions of the total content of amino acids as determined by the method of Rosen (1957). Due to the relatively low concentration of amino acids in amniotic fluid and the small volume available, no attempt was made to separate individual amino acids in this fluid.

Phosphorus was estimated colorimetrically (Allen, 1940); the procedure of Phillips (1958) was used for the preparation of phospholipid extracts and acidinsoluble phosphorus was estimated after precipitation with $20 \%(\mathrm{w} / \mathrm{v})$ trichloroacetic acid. Chloride (Schoenfeld \& Lewellen, 1964) and inorganic sulphate (Wainer \& Koch, 1962) were also determined colorimetrically. Bicarbonate was measured by back titration after liberation of all carbon dioxide with excess acid (Van Slyke, 1922) and sodium, potassium, calcium and magnesium were estimated with an atomic-absorption spectrophotometer. Determinations of the osmotic pressure were assessed by the freezing-point depression technique using a Knauer osmometer.

\section{RESULTS}

\section{Volume, $\mathrm{pH}$ and osmotic pressure determinations}

The volume, $\mathrm{pH}$ and osmotic pressure values of amniotic and allantoic fluids of sheep during early pregnancy are presented in Table 1. Although both

Table 1. Volume, $\mathrm{pH}$ and osmotic pressure of sheep fetal fluids during early pregnancy

\begin{tabular}{l|cc|ccc}
\hline \multirow{2}{*}{ Characteristic } & \multicolumn{2}{|c|}{ Amniotic fluid } & \multicolumn{3}{c}{ Allantoic fuid } \\
\cline { 2 - 6 } & Day 31 & Day 44 & Day 22 & Day 31 & Day 44 \\
\hline Volume (ml) & $2 \cdot 3 \pm 0 \cdot 7$ & $38 \cdot 8 \pm 3 \cdot 6$ & $7 \cdot 9 \pm 1 \cdot 4$ & $45 \cdot 7 \pm 5 \cdot 7$ & $95 \cdot 3 \pm 32 \cdot 3$ \\
pH & $7 \cdot 35 \pm 0 \cdot 09$ & $7 \cdot 35 \pm 0 \cdot 10$ & $7 \cdot 50 \pm 0.08$ & $7 \cdot 40 \pm 0 \cdot 04$ & $7 \cdot 35 \pm 0.05$ \\
Osmotic pressure & & & & & $214 \pm 8$ \\
(mosmol/litre) & $293 \pm 3$ & $292 \pm 2$ & $231 \pm 7$ & $224 \pm 7$ \\
\hline
\end{tabular}

Values are expressed as means \pm S.E.M.

fluids increased in volume as gestation proceeded, their rates of increase differed. Allantoic fluid displayed only a twofold increase in volume between Days 31 and 44 of pregnancy while a seventeenfold increase occurred in the amniotic fluid over the same period. At all stages studied, the volume of allantoic fluid was always greater than that of the amniotic fluid. There were only minor variations in the $\mathrm{pH}$ of the fluids with a mean value of approximately $\mathrm{pH} 7 \cdot 4$. Allantoic fluid was distinctly hypotonic with respect to amniotic fluid and no major changes in osmotic pressure were observed between stages of pregnancy. 
Organic compounds

The results of analyses for a number of organic components in sheep fetal fluids are given in Table 2. The concentration of total reducing sugar in allantoic fluid was high and it consisted predominantly of fructose. Glucose occurred in both amniotic and allantoic fluids but in low concentration relative

Table 2. Concentration of several organic components of sheep fetal fluids during early pregnancy

\begin{tabular}{|c|c|c|c|c|c|}
\hline \multirow{2}{*}{ Component } & \multicolumn{2}{|c|}{ Amniotic fluid } & \multicolumn{3}{|c|}{ Allantoic fluid } \\
\hline & Day 31 & Day 44 & Day 22 & Day 31 & Day 44 \\
\hline $\begin{array}{l}\text { Total reducing } \\
\text { sugar } \\
\text { Fructose } \\
\text { Glucose } \\
\text { Lactic acid } \\
\text { Sorbitol } \\
\text { Urea } \\
\text { Protein } \\
\text { Amino acids }\end{array}$ & $\begin{array}{l}82.5 \pm 1.4 \\
84.0 \pm 6.3 \\
22.6 \pm 0.5 \\
18.3 \pm 0.3 \\
1.75 \pm 0.17 \\
45.0 \pm 1.7 \\
14.0 \pm 0.9 \\
3.8 \pm 0.2\end{array}$ & $\begin{array}{l}66.4 \pm 5.5 \\
59.2 \pm 3.1 \\
25.1 \pm 0.7 \\
13.1 \pm 0.7 \\
3.50 \pm 0.38 \\
35.0 \pm 4.9 \\
14.8 \pm 1.0 \\
3.2 \pm 0.1\end{array}$ & $\begin{array}{l}276 \pm 8 \\
233 \pm 10 \\
31.0 \pm 2.2 \\
29.4 \pm 0.6 \\
3.79 \pm 0.32 \\
43.3 \pm 3.8 \\
77.0 \pm 2.7 \\
9.8 \pm 0.7\end{array}$ & $\begin{array}{cl}232 & \pm 29 \\
249 & \pm 20 \\
11.6 \pm 1.9 & \pm 19.6 \pm \\
19.6 & 0.7 \\
3.35 \pm & 0.23 \\
69.7 & 4.3 \\
75.4 & \pm .6 \\
9.6 \pm & \pm .9\end{array}$ & $\begin{array}{cc}721 & \pm 148 \\
723 & \pm 116 \\
33 \cdot 2 \pm & 2 \cdot 7 \\
12.2 \pm & 2 \cdot 5 \\
14 \cdot 4 \pm & 1 \cdot 7 \\
54 \cdot 0 \pm & 5 \cdot 8 \\
179 \pm & 15 \\
19.3 \pm & 3.5\end{array}$ \\
\hline
\end{tabular}

Values (means \pm S.E.M.) are expressed as $\mathrm{mg} / 100 \mathrm{ml}$ of fluid except for amino acids which are expressed as $\mu \mathrm{mol} / \mathrm{ml}$ of fluid.

to fructose. The concentration of fructose in allantoic fluid increased abruptly between Days 31 and 44 of pregnancy but, in amniotic fluid, it was much lower and remained essentially unaltered during this time. The lactic acid concentration was similar in both fluids and tended to decrease with increasing gestational age. Sorbitol increased in both fluids between Days 31 and 44 and occurred in greater concentration in allantoic fluid. Urea also tended to occur in greater concentration in allantoic fluid but its concentration did not increase with advancing pregnancy. The protein concentration of amniotic fluid was extremely low and did not alter between the stages studied. In allantoic fluid, however, the protein concentration was substantially higher and increased between Days 31 and 44 of pregnancy. The concentration of amino acids in

Table 3. Concentrations of individual amino acids and amine in allantoic fluid during early pregnancy in sheep

\begin{tabular}{l|lll}
\hline \multirow{1}{*}{ Component } & \multicolumn{3}{|c}{ Concentration (mM) at: } \\
& Day 22(4) & Day 31 (2) & Day 44 (2) \\
\hline Alanine & $1.49 \pm 0.15$ & $1.68 \pm 0.62$ & $3.57 \pm 0.57$ \\
Glutamic acid & $0.41 \pm 0.13$ & $0.41 \pm 0.03$ & $1.64 \pm 0.40$ \\
Glutamine & $1.52 \pm 0.18$ & $1.83 \pm 0.10$ & $3.86 \pm 0.19$ \\
Glycine & $1.06 \pm 0.12$ & $1.08 \pm 0.02$ & $1.79 \pm 0.63$ \\
Leucine/isoleucine & $0.58 \pm 0.03$ & $0.29 \pm 0.19$ & $0.58 \pm 0.20$ \\
Serine & $0.51 \pm 0.05$ & $0.91 \pm 0.05$ & $1.98 \pm 0.24$ \\
Threonine & $0.53 \pm 0.05$ & $0.48 \pm 0.29$ & $0.87 \pm 0.13$ \\
Valine & $0.63 \pm 0.05$ & $0.53 \pm 0.05$ & $0.63 \pm 0.05$ \\
Basic amino acids & $2.76 \pm 0.26$ & $2.47 \pm 0.20$ & $4.00 \pm 0.15$ \\
& & & \\
\hline
\end{tabular}

Values are expressed as means \pm S.E.M. The numbers of samples assayed are given in parentheses. 
amniotic fluid was much less than that in allantoic fluid and showed little variation between Days 31 and 44 of pregnancy. In allantoic fluid, however, there was a doubling in the concentration of amino acids between these times.

\section{Individual amino acids}

The concentrations of individual amino acids in allantoic fluid at each stage of pregnancy are given in Table 3 . Glutamic acid was the only acidic amino acid detected in the fluid and, at all stages of pregnancy, was present in considerably lower concentration than the related amine, glutamine. Alanine and glycine were the major neutral amino acids. Lower concentrations of serine, valine, threonine and leucine/isoleucine were also present. No attempt was made to separate the leucine and isoleucine as they made up a minor proportion of the total amino acids and their concentration showed little change with time. The basic amino acids made up approximately $30 \%$ of the total amino acids at all stages of pregnancy. On high-voltage electrophoresis, these amino acids separated into three distinct zones: one corresponding to arginine, one to lysine, and a fast running zone which was not identified. The arginine and lysine zones made up 75 to $90 \%$ of the total basic amino acids and were present in equal proportions at the three stages of pregnancy. However, paper chromatography of these zones indicated that each contained more than one ninhydrinreactive compound and so they are not listed separately in the table. The fast running compound made up the remaining 10 to $25 \%$ and had a mobility 1.8 times that of lysine, using phthalate buffer, and 1.8 times that of alanine, using formic acid-acetic acid-cadmium acetate buffer at $\mathrm{pH} 1.81$ (Atfield \& Morris, 1961). No amino acid or ninhydrin-reactive amine tested was found to have these mobilities.

Between Days 22 and 31, there was little change in the concentration of the amino acids isolated. However, substantial increases occurred in the concentrations of alanine, glutamic acid, glutamine and serine between Days 31 and 44 of pregnancy. Combined, these increases accounted for $65 \%$ of the rise in the total content of amino acids between these times. Proportionately smaller increases occurred in the concentration of glycine and the basic amino acids over this time.

\section{Distribution of phosphorus}

The concentration of phosphorus was slightly higher in allantoic than in amniotic fluid and did not change greatly in either fluid between the stages of pregnancy studied (Table 4). The bulk of the phosphorus was isolated in the acid-soluble fraction after acid precipitation and was present mainly in the inorganic form. Acid-insoluble and lipid phosphorus occurred in the fluids in low concentration when compared to that of the acid-soluble form.

\section{Ionic composition}

The concentrations of several cations and anions in sheep fetal fluids during early pregnancy are shown in Table 5. Sodium, potassium and chloride ions were present in higher concentrations in amniotic fluid than in allantoic fluid in all samples analysed. At the latest stage of pregnancy investigated, calcium 
Table 4. Distribution of phosphorus in sheep fetal fluids during early pregnancy

\begin{tabular}{|c|c|c|c|c|c|}
\hline \multirow{2}{*}{$\begin{array}{l}\text { Form of } \\
\text { phosphorus }\end{array}$} & \multicolumn{2}{|c|}{ Amniotic fluid } & \multicolumn{3}{|c|}{ Allantoic fluid } \\
\hline & Day 31 & Day 44 & Day 22 & Day 31 & Day 44 \\
\hline $\begin{array}{l}\text { Total } \\
\text { Acid-soluble } \\
\text { Acid-insoluble } \\
\text { Lipid } \\
\text { Inorganic }\end{array}$ & $\begin{array}{l}1.18 \pm 0.19 \\
1.22 \pm 0.13 \\
0.01 \pm 0.00 \\
0.02 \pm 0.01 \\
1.55 \pm 0.18\end{array}$ & $\begin{array}{l}2.31 \pm 0.53 \\
1.83 \pm 0.12 \\
0.75 \pm 0.26 \\
0.43 \pm 0.09 \\
1.80 \pm 0.20\end{array}$ & $\begin{array}{l}4.43 \pm 0.62 \\
3.93 \pm 0.23 \\
0.20 \pm 0.08 \\
0.55 \pm 0.13 \\
2.66 \pm 0.56\end{array}$ & $\begin{array}{l}3 \cdot 14 \pm 0.86 \\
3 \cdot 45 \pm 0.29 \\
1 \cdot 83 \pm 0.54 \\
0 \cdot 10 \pm 0.04 \\
2 \cdot 65 \pm 0.55\end{array}$ & $\begin{array}{l}3.34 \pm 0.97 \\
2 \cdot 31 \pm 0.34 \\
0.93 \pm 0.21 \\
0.38 \pm 0.13 \\
2 \cdot 13 \pm 0.39\end{array}$ \\
\hline
\end{tabular}

All values are expressed as $\mathrm{mg} / 100 \mathrm{ml}$ and are the means \pm S.E.M. for four samples.

and magnesium ions occurred in higher concentrations in allantoic fluid than in amniotic fluid. The concentration of ammonium ions was low in both fluids and did not change with increasing gestational age. Although the concentration of potassium ions in amniotic fluid showed little change with time, it decreased slightly in allantoic fluid between Days 22 and 44 of pregnancy. The concentrations of calcium and magnesium in amniotic fluid decreased very slightly between Days 31 and 44 and increased almost twofold in the allantoic fluid during the same period. Small increases in the concentrations of chloride and bicarbonate ions were observed in amniotic fluid between Days 31 and 44 but in the allantoic fluid, the concentration of chloride ions remained essentially unchanged while the concentration of bicarbonate ions decreased. Negligible amounts of inorganic sulphate could be detected in the fluids.

Table 5. Ionic composition of sheep fetal fluids during early pregnancy

\begin{tabular}{|c|c|c|c|c|c|}
\hline \multirow{2}{*}{$\begin{array}{c}\text { Ionic } \\
\text { component }\end{array}$} & \multicolumn{2}{|c|}{ Amniotic fluid } & \multicolumn{3}{|c|}{ Allantoic fluid } \\
\hline & Day 31 & Day 44 & Day 22 & Day 31 & Day 44 \\
\hline $\begin{array}{l}\mathrm{Na}^{+} \\
\mathrm{K}^{+} \\
\mathrm{Ca}^{++} \\
\mathrm{Mg}^{++} \\
\mathrm{NH}_{4}^{+} \\
\mathrm{Cl}^{-} \\
\mathrm{HCO}_{3}-\end{array}$ & $\begin{array}{c}136 \pm 14 \\
16 \cdot 8 \pm 1 \cdot 8 \\
2 \cdot 36 \pm 0.18 \\
2 \cdot 05 \pm 0 \cdot 85 \\
0 \cdot 20 \pm 0 \cdot 02 \\
124 \pm 10 \\
10 \cdot 4 \pm 2 \cdot 1\end{array}$ & $\begin{array}{cl}139 & \pm 4 \\
18 \cdot 6 & \pm 1 \cdot 1 \\
1 \cdot 30 \pm 0.07 & \pm 0.07 \\
1 \cdot 83 \pm 0.82 \\
0 \cdot 17 \pm 0.01 \\
123 \pm 2 \\
23 \cdot 4 \pm 0.5\end{array}$ & $\begin{array}{c}77.5 \pm 6 \cdot 1 \\
6 \cdot 30 \pm 0.37 \\
1 \cdot 74 \pm 0 \cdot 14 \\
2.56 \pm 0.57 \\
0.14 \pm 0.03 \\
49.3 \pm 6.2 \\
31.4 \pm 0.8\end{array}$ & $\begin{array}{c}88.9 \pm 2.2 \\
5.33 \pm 0.91 \\
2.28 \pm 0.22 \\
2.99 \pm 0.76 \\
0.19 \pm 0.03 \\
61.3 \pm 4 \cdot 6 \\
28.1 \pm 0.8\end{array}$ & $\begin{array}{r}79.0 \pm 11.7 \\
3.13 \pm 0.44 \\
4.26 \pm 0.56 \\
6.69 \pm 1.70 \\
0.14 \pm 0.04 \\
64.8 \pm 10.5 \\
18.1 \pm 2.4\end{array}$ \\
\hline
\end{tabular}

Values are expressed as mequiv./litre and are the means \pm S.E.M. for four samples.

\section{DISCUSSION}

The results demonstrate large changes in the chemical composition of sheep allantoic fluid and the relatively constant composition of amniotic fluid during early pregnancy. McDougall (1949) also noted the constant composition of sheep amniotic fluid between Days 28 and 140 of pregnancy and suggested that this fetal fluid is in Donnan equilibrium with the maternal serum, and that the chemical differences between amniotic and allantoic fluids are due to the intervention of the digestive tract and kidney of the fetus. Alexander, Nixon, Widdas \& Wohlzogen (1958a) agree that amniotic fluid is closely related in 
many ways to fetal or maternal plasma but indicate that admixture with fetal urine may occur in the later part of pregnancy. It has been postulated that urine from the sheep fetus passes into the allantoic sac through the urachus up to a gestational age of 90 days and thereafter passes more and more into the amniotic sac due to the occlusion of the urachus and the opening of the urethra (see Vernier \& Smith, 1968).

The sheep embryo mesonephros is functionally active at 18 days after fertilization (Davies, 1952) and the appearance of this activity is followed by the formation of fluid within the allantoic sac having a relatively high fructose concentration. In ewes and certain other mammals with epitheliochorial or syndesmochorial placentae, fructose is essentially a fetal and placental product (Hers, 1957, 1960; Britton, Huggett \& Nixon, 1967) and the results of the present investigation indicate that it is the main free reducing sugar present in the fetal fluids. Its increase in concentration in allantoic fluid between Days 31 and 44 of pregnancy presumably reflects an increase in the release of fetal urine into the allantoic sac during this time (see Alexander, Britton \& Nixon, 1966). Increased haematotrophe, resulting from more advanced placentation, must also be instrumental in the increased formation of fructose in allantoic fluid, since Britton et al. (1967) have indicated that maternal blood glucose, through its conversion to sorbitol in the placenta, is the major and possibly only precursor of the fetal keto-hexose. It is not known what part fructose plays in the fetal fluids of sheep since its utilization as an energy substrate by the fetus appears to be limited (Alexander et al., 1966). However, the consumption of fructose by fetal red cells or the perfused placenta is increased by glucose deprivation and may be important in the synthesis of fetal tissue in the period of rapid fetal growth in the last days in utero (see Huggett, 1961). Alexander, Huggett, Nixon \& Widdas (1955) have also suggested that the presence of fetal fructose may play a rôle in the survival of the developing fetus in adverse circumstances since its rate of production is continuous and is independent of the glucose concentration in both maternal and fetal bloods.

The protein, urea, chloride and cation values reported in the present investigation are in good agreement with those of McDougall (1949) and Alexander et al. (1958a). The sums of the anion concentrations are, on the average, within $\pm 6 \%$ of the cationic concentration for amniotic fluid and $\pm 4 \%$ for allantoic fluid. The osmotic pressure of amniotic fluid, as calculated from the sums of the electrolyte concentrations, is in close agreement with values determined by the freezing-point depression technique indicating that the analyses for the main ionic constituents are reasonably complete. In the case of allantoic fluid, fructose also contributes substantially to the osmotic pressure, especially on Day 44 of pregnancy. However, the tonicity of this fluid remains lower than that of amniotic fluid due mainly to its lower concentrations of sodium and chloride ions. The formation of allantoic fluid, which is hypotonic with respect to amniotic fluid, further suggests the release of fetal urine into the allantoic sac. Alexander et al. (1958a) demonstrated that during the greater part of pregnancy, fetal urine is definitely hypotonic with respect to plasma and showed that allantoic fluid is also initially hypotonic but rises in tonicity towards term due to changes in the rates of water and electrolyte resorption and the 
formation of hypertonic urine (Alexander, Nixon, Widdas \& Wohlzogen, 1958b).

A urinary origin for at least some of the allantoic amino acids seems probable from the results of the present study since the concentration of these compounds is higher in this fluid than in amniotic fluid and increases between Days 31 and 44 of pregnancy. Alexander et al. (1958a) also found that amino acid nitrogen concentration was highest in allantoic fluid. Sheep fetal blood possesses a higher concentration of amino acids than maternal blood and, on perfusing the isolated fetus, there is a depletion of the essential amino acids in the plasma (Alexander, Britton, Nixon \& Cox, 1970). Substantial increases in the concentrations of alanine, glutamic acid and serine in allantoic fluid with increasing gestational age suggest that the fetus releases a number of amino acids that are regarded as being non-essential for the tissues of the sheep (Downes, 1961). Amino acids that do appear to be essential in the sheep were either not detected or were present in allantoic fluid in low concentrations which did not change substantially between the stages of pregnancy studied. The relatively high concentration of glutamine in this fluid may partially be attributed to conversion reactions in the fetus involving glutamic acid.

In conclusion, the results support the suggestion by McDougall (1949) that a direct transfer of materials between the amniotic and allantoic fluids across the placental membranes is improbable. Furthermore, changes in the concentration of a number of components in allantoic fluid with increasing gestational age suggest increased release of fetal urine and imply that major developmental changes in metabolic activity are occurring in the sheep fetus between Days 31 and 44 of pregnancy.

\section{ACKNOWLEDGMENTS}

The authors are indebted to Professor C. W. Emmens for his interest and criticism. The work was supported by a Ford Foundation Grant.

\section{REFERENCES}

Alexander, D. P., Britton, H. G. \& Nixon, D. A. (1966) Observations on the isolated foetal sheep with particular reference to the metabolism of glucose and fructose. 7 . Physiol., Lond. 185, 382.

Alexander, D. P., Britton, H. G., Nixon, D. A. \& Cox, B. D. (1970) Amino acid metabolism in the sheep foetus. Biologia Neonat. 15, 304.

Alexander, D. P., Huggetr, A. Sr.G., Nixon, D. A. \& Widdas, W. F. (1955) The placental transfer of sugars in the sheep: the influence of concentration gradient upon the rate of hexose formation as shown in umbilical perfusion of the placenta. F. Physiol., Lond. 129, 367.

Alexander, D. P., Nixon, D. A., Widdas, W. F. \& Wohlzogen, F. X. (1958a) Gestational variations in the composition of the foetal fluids and foetal urine in the sheep. F. Physiol., Lond. 140, 1.

Alexander, D. P., Nixon, D. A., Widdas, W. F. \& Wohlzogen, F. X. (1958b) Renal function in the sheep foetus. F. Physiol., Lond. 140, 14.

Allen, R. J. L. (1940) The estimation of phosphorus. Biochem. F. 34, 858.

Atfield, G. N. \& Morris, G. J. O. R. (1961) Analytical separations by high-voltage paper electrophoresis. Amino acids in protein hydrolysates. Biochem. 7. 81, 606.

Barker, J. N. \& Britton, H. G. (1957) The enzymatic estimation of $\mathrm{L}(+)$ lactic acid. F. Physiol, Lond. 138, 3P.

Block, R. J., Durrum, E. L. \& Zweig, G. (1958) A manual of paper chromatography and paper electrophoresis, 2nd edn, p. 575. Academic Press, New York.

Britton, H. G., Hugcetr, A. St.G. \& Nixon, D. A. (1967) Carbohydrate metabolism in the sheep placenta. Biochim. biophys. Acta, 136, 426. 
DAvies, J. (1952) Correlated anatomical and histochemical studies on the mesonephros and placenta of the sheep. Am. 7. Anat. 91, 263.

Downes, A. M. (1961) On the amino acids essential for the tissues of the sheep. Aust. F. biol. Sci. 14, 254.

Grünbaum, B. W. \& Pace, N. (1965) Microchemical urinalysis. 1. Simplified determinations of ammonia, urea, creatinine, creatine, phosphate, uric acid, glucose, chloride, calcium, and magnesium. Microchem. F. 9, 166.

HERs, H. G. (1957) Presence of sorbitol in seminal vesicles and in foetal blood of the sheep. Biochem. $\mathcal{J}$. 66, 30p.

Hers, H. G. (1960) Le mécanisme de la formation du fructose séminal et du fructose foetal. Biochim. biophys. Acta, 37, 127.

HuggetT, A. ST.G. (1961) Carbohydrate metabolism in the placenta and foetus. Br. med. Bull. 17, 122.

Huggett, A. St.G. \& Nixon, D. A. (1956) Enzymatic determination of blood glucose. Biochem. $\mathcal{F}$. $66,12 \mathrm{P}$.

Lowry, O. H., Rosebrough, N. J., Farr, A. L. \& Randall, R. J. (1951) Protein measurement with Folin phenol reagent. J. biol. Chem. 193, 265.

MaDougall, E. I. (1949) The composition of foetal fluids of sheep at different stages of gestation. Biochem. 7. 45, 397.

MANN, T. (1948) Fructose content and fructolysis in semen. Practical application in the evaluation of semen quality. 7. agric. Sci., Camb. 38, 323.

Murdoch, R. N. (1970) Uterine endometrial phosphomonoesterases in relation to implantation in the ewe and rabbit doe. Aust. F. biol. Sci. 23, 1089.

O'Shea, T. \& Wales, R. G. (1965) Metabolism of sorbitol and fructose by ram spermatozoa. 7 . Reprod. Fert. 10, 353.

Phillirs, G. B. (1958) The isolation and quantitation of the principal phospholipid components of human serum using chromatography on salicic acid. Biochim. biophys. Acta, 29, 594.

Rosen, H. (1957) A modified ninhydrin colorimetric analysis for amino acids. Archs Biochem. Biophys. $67,10$.

Schoenfeld, R. G. \& Lewellen, C. J. (1964) A colorimetric method for determination of serum chloride. Clin. Chem. 10, 533.

SoмоGyi, M. (1952) Notes on sugar determination. 7. biol. Chem. 195, 19.

VAN SLyKe, D. D. (1922) Studies of acidosis. 18. Determination of bicarbonate concentration of the blood and plasma. F. biol. Chem. 52, 495.

Vernier, R. L. \& SMith, F. G., JR (1968) Fetal and maternal kidney. In: Biology of Gestation, Vol. 2, p. 225. Ed. N. S. Assali. Academic Press, New York.

WAINER, A. \& Koch, A. L. (1962) Determination of inorganic sulphate in urine using barium chloranilate. Analyt. Biochem. 3, 457.

Whrte, I. G. (1959) Studies on the metabolism of glycerol, fructose and lactic acid with particular reference to semen. Aust. F. exp. Biol. med. Sci. 37, 441. 